\title{
Strategi Inovasi Perusahaan Keluarga Sekala UKM Studi Kasus Industri Batik Daerah Istimewa Yogyakarta
}

\author{
Antori \\ Dosen Tetap Akademi Ilmu Pelayaran Nusa Tenggara \\ Email: antori@aipnusra.ac.id
}

\begin{abstract}
This research is conducted by qualitative approach of case study method, the main purpose is to explore the strategic actions of small-scale family enterprises in batik industry based on innovation strategy (SI). The data was collected through in-depth interviews of ten SME batik industry players in Yogyakarta. The findings show that the pattern of SI contractor business actors tends to innovate products and distribution innovations that serve as an alternative solution to overcome the problems encountered. In addition, found the slow growth of SMEs scale batik companies have been due to in addition to prioritizing external problems, but also the lack of correlation between solutions taken with the problems encountered.
\end{abstract}

Keywords: Innovation Strategy, family company, SME, batik industry.

\section{PENDAHULUAN}

UMKM sudah ada sejak masa orde baru tetapi belum mendapat perhatian serius dari pemerintah.Namun saat ini, pemerintah sudah memberikan perhatian serius pada UMKM karena terbukti mampu bertahan terhadapguncangan krisis ekonomi serta peranannya yang besar dalam perekonomian nasional. Hal tersebut bisa dilihat dari perkembangan UMKM dan sumbangsihnya terhadap PDB nasional pada tabel 1 berikut:

Tabel 1. Data perkembangan UKM dan Sumbangsihnya pada PDB

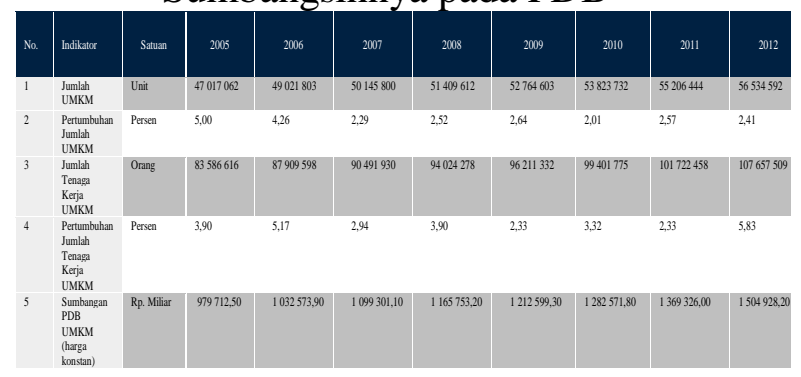

Diakses /www.bps.go.id. 2016

Salah satu daerah yang senantiasa mengalami pertumbuhan UMKM hingga 10\% pertahun yaitu Daerah Istimewa Yogyakarta (DIY), Hingga akhir desember 2015 Dinas Koperasi dan UKM DIY mencatat total jumlah UMKM sebanyak 147.267 (jogja.antaranews.com, 2016).Salah satu Industri dalam sekala UMKM adalah Industri batik yang merupakan bagian dari produk fashion atau pakaian yang bisa dikategorikan dalam sektor ekonomi kreatif.seperti yang disampaikan Badan Ekonomi Kreatif (Bekraf) Triawan Munaf bahwa ada tiga produk ekonomi kreatif yang menyumbang besar pada pertumbuhan ekonomi Indonesia yaitu produk fashion, kuliner dan kerajinan. Ketiganya menyumbang lebih dari 50 persen kontribusi sektor ekonomi kreatif terhadap Produk Domestik Bruto (PDB) nasional (Kompas.com, 2016).Selain itu, industri batik juga terus mengalami perkembangan dari tahun ke tahun yang memiliki peranan besar dalam penyerapan tenaga kerja seperti yang diuraikan pada tabel 2 perkembangan industri batik berikut.

Tabel 2. Data Perkembangan Industri Batik 2011-2015

\begin{tabular}{|c|c|c|}
\hline Tahun & $\begin{array}{l}\text { Jumlah Unit } \\
\text { Usaha ( Unit) }\end{array}$ & $\begin{array}{l}\text { Jumlah Tenaga } \\
\text { Kerja (orang) }\end{array}$ \\
\hline 2011 & 41.623 & 173.829 \\
\hline 2012 & 43.704 & 182.521 \\
\hline 2013 & 45.015 & 187.996 \\
\hline 2014 & 46.365 & 193.635 \\
\hline 2015 & 47.755 & 199.444 \\
\hline
\end{tabular}

Data diolah, diakses dari finance.detik.com (2016).

DIY yang terus mengalami pertumbuhan dengan jumlah mencapai 8.000 
pelaku usaha meningkat dibandingkan dengan 2013 yang masih berjumlah 3000 UKM pelaku usaha batik yang tersebar di lima kabupaten/kota (jogja.antaranews.com,). Perkembangan pesat UKM termasuk di dalamnya industri batik tersebut tidak serta merta tanpa menghadapi berbagai permasalahan. Sudaryanto dkk (2011) mengatakan bahwa pemberdayaan UKM ditengah arus globalisasi dan tingginya persaingan membuat UKM harus mampu menghadapi tantangan global seperti meningkatkan inovasi produk dan jasa, pengembangan sumber daya manusia dan teknologi.tantangan sekaligus peluang terkait pasar bebas yang sudah berlaku pada akhir tahun 2015 yaitu Asean Economic Comunity (AEC) atau biasa juga disebut Masyarakat Ekonomi ASEAN (MEA), Pada penelitian Rahadi (2016) memaparkan bahwa beberapa kata kunci penting untuk kategori tantangan bagi pemilik usaha UKM di Indonesia saat menghadapi AEC yaitu tenaga kerja, modal, persaingan, sistem penjualan, inovasi, keuangan, birokrasi, dan pemerintah. Sedangkan untuk peluang, kata kuncinya ialah adanya AEC termasuk menjadi pasar potensial, kreativitas, peluang ekspor, perjuangan dan daya tahan dari pemilik bisnis lokal, dan pengetahuan pasar lokal.

Batik Indonesia secara resmi telah dikukuhkan menjadi warisan budaya dunia oleh UNESCO pada tangaal 2 Oktober 2009. Pengukuhan tersebut turut mendongkrak popularitas dan pertumbuhan batik hingga mampu menembus pasar internasional terbukti dengan tingkat pertumbuhan peminat manca negara dilihat peningkatan nilai ekspor batik Indonesia dari tahun ke tahun (finance.detik.com, 2016).Hal ini terbukti dengan meningkatnya nilai ekspor batik dari tahun ke tahun, bisa dilihat pada 3 berikut.

Tabel 3. Pertumbuhan Nilai Ekspor Batik Indonesia

\begin{tabular}{|l|l|l|}
\hline Tahun & Jumlah & Nilai Ekspor \\
\hline 2011 & Rp 43,961 & Triliun \\
\hline 2012 & Rp 46,159 & Triliun \\
\hline
\end{tabular}

\begin{tabular}{|l|l|l|}
\hline 2013 & Rp 47,543 & Triliun \\
\hline 2014 & Rp 48,970 & Triliun \\
\hline 2015 & Rp 50,439 & Triliun \\
\hline
\end{tabular}

(finance.detik.com, 2016).

Meskipun ekspor terus meningkat, namun impor tekstil dengan desain batik dari China tidak bisa dielakan.Bahkan nilai impornya sudah mencapai jutaan dolar Amerika Serikat (AS), tercatat sebanyak 1.037 ton produk batik yang masuk dari China ke Indonesia dengan nilai US\$ 30 juta. Impor terbesar adalah untuk jenis kain tenun dicetak batik, yaitu sebanyak 677,4 ton senilai US\$ 23,3 juta dan kain tenun yang dicetak dengan proses batik sebanyak 199,2 ton dengan nilai US\$ 1,8 juta pada 2012 lalu. (bisnis.liputan6.com/2015). Selain itu menurut penelitian $40 \%$ pelaku usaha pemula tidak mampu bertahan pada tahun pertama. Sementara itu, dari $60 \%$ yang bertahan, $80 \%$ diantaranya rontok di 5 tahun pertama (bisnis.com, 2013).Dengan demikian perlu diperhatikan faktor-faktor kunci yang mempengaruhi keberhasilan UMKM, perhatian perlu diarahkan pada tiga hal yaitu: (1) karakteristik entrepreneur, (2) karakteritik UMKM itu sendiri dan (3) tipe strategi yang digunakan (Storey , 1994).Selama ini perhatian banyak diarahkan pada faktor yang pertama dan yang ke dua serta sedikit sekali yang memberi perhatian pada faktor yang ke tiga, hal tersebut bisa dimaklumi karena termasuk dalam kategori pelaku. Maka dari itu pada penelitian kali ini perhatian akan diarahkan pada faktor yang ke tiga yaitu tipe strategi yang digunakan dalam hal ini ialah Strategi Inovasi (SI) karena salah satu karateristik UKM yang mampu bertahan ialah kemampuannya dalam berinovasi terutama yang masuk dalam industry kreatif.Lo (2008) bahwa inovasi mode atau trend fashion merupakan kelompok konsumen yang sangat vital bukan hanya karena pembelian mereka membawa arus kas positif tetapi juga karena legitimasi mouth of mouth mereka pada mode baru.Pachouru \& Sharma (2016) memaparkan bahwa inovasi memainkan peran penting 
dalam membentuk daya saing industri dan perusahaan dari negara mana pun. penelitian Hartini (2012) menunjukan inovasi perusahaan tidak mempengaruhi kinerja perusahaan secara langsung, tapi berpengaruh signifikan terhadap kualitas produk. Adapun kualitas produk mempengaruhi signifikan terhadap kinerja perusahaan. Pada penelitian tersebut menyarankan perlu adanya dilakukan penelitian eksplorasi inovasi perusahaan seperti apa yang dibutuhkan perusahaan sehingga meningkatkan kualitas produk yang ditawarkan. Peneltian tersebut koheren dengan Hasil penelitian Beyene (2012) yangmenunjukkan bahwa strategi inovasi positif berkaitan dengan kinerja inovasi produk. Selanjutnya, ukuran perusahaan dan jenis kepemilikan berpengaruh pada strategi inovasi terhadap kinerja inovasi produk.

Terkait dengan perusahaan keluarga, beberapa hal menunjukkan perbedaan yang signifikan antara perusahan keluarga dan non-keluarga sekala UKM pada setiap tahap dari proses inovasi, hal paling utama ialah menunjukkan bahwa perilaku investasi inovasi lebih kompleks dan beragam di UKM perusahaan keluarga dari pada dalam bisnis perusahaan keluarga yang besar. Di satu sisi, UKM perusahaan keluarga lebih cenderung untuk berinvestasi dalam inovasi daripada UKM non keluarga. Mengenai hasil inovasi, UKM perusahaan keluarga ditemukan setidaknya sama efektif dalam mencapai inovasi produk dan rata-rata lebih efektif dari pada UKM non-keluarga dalam mencapai proses inovasi (Classen dkk, 2014).Rettab dan Azzam, (2011) dalam Zou dkk, (2014) menemukan bahwa bisnis keluarga mengungguli bisnis non-keluarga dalam sektor perdagangan dan konstruksi.Namun, Kinerja keluarga bisnis-bisnis paling lemah di sektor manufaktur dan jasa. Hasil penelitian empiris yang dilakukan oleh Zou dkk (2014) konsisten dengan dengan temuan tersebut bahwa kinerja perusahaan bukan keluarga lebih efisien dari pada perusahaan keluarga.

Perusahaan harus terus memperkenalkanInovasi yang merupakan suatu proses kegiatan untuk menciptakan produk baru atau layanan, proses Teknologi baru, organisasi baru, atau peningkatan produk yang ada atau layanan, proses teknologi yang ada dan organisasi yang ada (Ramadani \& Gerguri, 2010).Memasarkan barang atau jasabaru, atau memperbaiki proses produksi, pengiriman dan bisnis diimplementasikan sengaja dan dengan cara sistemik, sekelompok kegiatan ini yang disebut sebagai strategi inovasi (Frenz \& Lambert, 2012). Strategi inovasi adalah sebuah konsep yang memberikan wawasan lebih tentang bagaimana perusahaan bersaing pada pasar yang tidak stabil dan mempertahankan atau menciptakan keunggulan kompetitif baru. Pendorong utama strategi inovasi ialah kepemimpinan kewirausahaan, diversifikasi Tim Manajemen Top, dan mekanisme belajar yang disengaja, sehingga pertumbuhan tinggi dapat dicapai melalui merintis nilai dan perintis tidak hanya oleh teknologi (Kataria, 2013).

Pertanyaan besar pada penelitian ini untuk ditemukan jawabannya adalah sebagai berikut:

1. Pola inovasi seperti apa yang dilakukan perusahaan keluarga skala UKM pada industri batik Yogyakarta?

2. Bagaimana strategi inovasi yang dilakukan perusahaan keluarga skala UKM pada industri batik Yogyakarta?

3. Apakah pola dimensi inovasi yang dilakukan menjamin perusahaan keluarga skala UKM pada industri batik Yogyakarta bisa bersaing dalam jangka panjang?

Pada penelitian ini difokuskan pada kajian strategi inovasi pada perusahaan keluarga skala UKM industry batik, dalam kasus penelitian ini dikhususkan pada industry batik sekala UKM di DIY.Miles dan Snow (1978) mengklasifikasikan tipologi perusahaan menjadi empat kelompok yang berbeda, yaitu Defender, Analyzer, dan Prospectordan reactor.

Defender adalah perilaku strategi yang dengan sengaja memberlakukan dan mempertahankan lingkungan dalam bentuk stabil agar sesuai dengan organisasinya.Beberapa tindakan ekonomis yang sering muncul diantaranya membuat harga yang kompetitif atau membuat produk berkualitas tinggi (Miles, 1978).

Analyzer adalah kombinasi dari tipe defender dan prospector dan merepresentasikan alternative yang cukup layak. Analyzer seungguhnya merupakan organisasi yang berupaya keras untuk 
meminimalisir resiko sembari memaksimalkan peluang untuk mendapatkan keuntungan.

$$
\text { Prospector memperlakukan }
$$

lingkungan lebih dinamis dibandingkan yang lainnya di dalam sebuah industry yang sama, tidak seperti defender yang kesuksesan utamanya datang dari efisiensi dalam melayani area yang cenderung stabilKemampuan utama prospector adalah menemukan dan mengeksploitasi produk dan peluang pasar yang baru.

Tipe reactor menunjukan pola penyesuaian terhadap lingkungan yang inkonsisten dan tidak stabil. Tipe ini memiliki keruangan seprangkat mekanisme respon dimana hal itu dapat secara konsisten meletakkan pada efek saat lingkungan berubah.

Berikut penjelasan tentangstrategi inovasi menurut beberap penulis:

\begin{tabular}{|c|c|}
\hline Penulis & Penjelasan \\
\hline $\begin{array}{l}\text { (Kataria, } \\
\text { 2013). }\end{array}$ & $\begin{array}{l}\text { Strategi inovasi } \\
\text { adalah sebuah konsep } \\
\text { yang memberikan } \\
\text { wawasan lebih tentang } \\
\text { bagaimana perusahaan } \\
\text { bersaing pada pasar } \\
\text { yang tidak stabil dan } \\
\text { mempertahankan atau } \\
\text { menciptakan } \\
\text { keunggulan kompetitif } \\
\text { baru. Pendorong } \\
\text { utama strategi inovasi } \\
\text { ialah kepemimpinan } \\
\text { kewirausahaan, } \\
\text { diversifikasi Tim } \\
\text { Manajemen Top, dan } \\
\text { mekanisme belajar } \\
\text { yang disengaja, } \\
\text { sehingga pertumbuhan } \\
\text { tinggi dapat dicapai } \\
\text { melalui merintis nilai } \\
\text { dan perintis tidak } \\
\text { hanya oleh teknologi. }\end{array}$ \\
\hline $\begin{array}{l}\text { (Chesbrough, } \\
\text { 2010). }\end{array}$ & $\begin{array}{lr}\quad \text { Strategi } & \text { Inovasi } \\
\text { bekerja } & \text { melalui } \\
\text { inovasi } & \text { produk } \\
\text { teknologi, } & \text { Inovasi } \\
\text { organisasi } & \text { dan }\end{array}$ \\
\hline
\end{tabular}

\begin{tabular}{|c|c|}
\hline & $\begin{array}{l}\text { manajerial } \\
\text { inovasi model bisnis) } \\
\text { tidak } \\
\text { menyebabkan } \\
\text { penciptaan nilai tanpa } \\
\text { inovasi produk } \\
\text { teknologi }\end{array}$ \\
\hline $\begin{array}{ll}\text { Frenz } \quad \& \\
\text { Lambert, } \\
\text { 2012). }\end{array}$ & 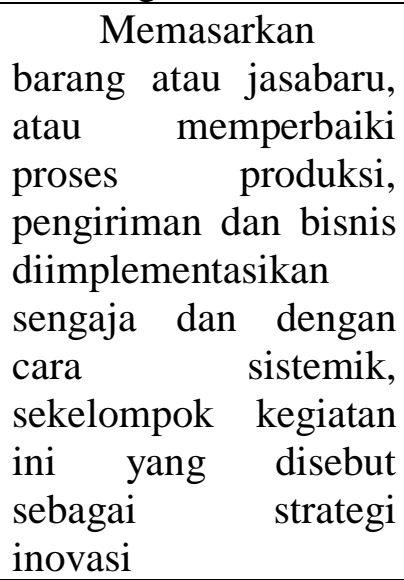 \\
\hline Preda & $\begin{array}{l}\text { Memberikan } \\
\text { pengertian inovasi } \\
\text { dengan } \\
\text { mengklasifikasikannya } \\
\text { dalam beberapa hal } \\
\text { yaitu memperkenalkan } \\
\text { produk baru atau } \\
\text { modifikasi produk } \\
\text { yang sudah ada, } \\
\text { sebuah inovasi proses } \\
\text { baru di dalam } \\
\text { industry, penemuan } \\
\text { pasar baru, } \\
\text { mengembangkan } \\
\text { sumber-sumber } \\
\text { pasokan baru dengan } \\
\text { bahan baku, } \\
\text { Perubahan lain dalam } \\
\text { organisasi. }\end{array}$ \\
\hline
\end{tabular}

Mengenai tipologi atau jenis inovasi,Damanpour (1991) menunjukkan tiga pasang jenis inovasi yaitu:(1). Inovasi administrasi - inovasi teknis( 2). Inovasi Proses - inovasi produk (3). Inovasi Radikal Inovasi Inkremental.

Pendekatan Penelitian

Penelitian ini menggunakan pendekatan penelitian kualitatif dengan metode studi kasus yaitu inovasi pada industri batik skala UKM, dikarenakan subjek kajian 
memerlukan eksplorasi dan penjelasan yang berupa kebijakan atau keputusan strategis yang mampu dinilai melalui pengamatan dan pemahaman konsep secara mendalam melalui perolehan informasi mendalam dari informan. Objek penelitian ini adalah perushaaan skala UKM pada Industri batik di Yogyakarta. instrumen utama untuk mengumpulkan data adalah peneliti maupun dengan bantuan orang lain (Human instrument). Dalam penelitian ini, diperlukan wawasan dan pengetahuan dengan mempelajari teori yang ada terkait strategi inovasi dengan mengkombinasikannnya dengan data yang tepat diperoleh secara langsung dengan pihak terkait sesuai dengan objek penelitian ini.Jenis data yang digunakan dalam penelitian ini adalah data primer dan data skunder. Data primer dalam penelitian ini diperoleh melalui wawancara dengan pihak terkait dalam hal ini perusahaan keluarga sekala UKM pada industry batik di Yogyakarta, sedang data sekunder diperoleh melalui lewat website terkait dan dokumentasi yang mendukung penelitian ini.Sumber data dalam penelitian ini adalah dari informan yaitu pelaku usaha batik skala UKM berjumlah sepuluh dengan dua pelaku usaha tiap kabupaten dan kota di provinsi DIY.

Dalam penelitian ini menggunakan purposif dalam menentukan dan menemukan informan, peneliti membuat kriteria yang dapat menjadi informan yaitu pemilik atau pengelola perusahaan keluarga sekala UKM pada Industri batik di Yogyakarta. Prosedur purposif atau mekanisme disengaja dijelaskan Afrizal (2014:140) bahwa sebelum melakukan penelitian para peneliti menetapkan kriteria tertentu yang mesti dipenuhi oleh orang yang akan dijadikan sumber informasi, berdasarkan kriteria yang sudah ditetapkan peneliti telah mengetahui identitias orang-orang yang akan dijadikan infoman penelitian sebelum penelitian dilakukan. Pada akhirnya, diharapkan mampu memperoleh data yang cukup dari informan untuk menjawab dan menyelesaikan permasalahn dalam peneltian ini.
Tabel 4. Profil Responden

\begin{tabular}{|c|c|c|c|c|c|c|}
\hline Nama & Lokasi & Pendidikan & Generasi & $\begin{array}{l}\text { Tenaga } \\
\text { Kerja }\end{array}$ & $\begin{array}{l}\text { Tahun } \\
\text { Pendirian }\end{array}$ & Usia \\
\hline $\begin{array}{l}\text { Kusumavignette } \\
\text { batik }\end{array}$ & Yogyakarta & S1 & 2 & 9 & 2007 & 41 \\
\hline Narendra Batik & Yogyakarta & S1 & 1 & 9 & 2000 & 48 \\
\hline $\begin{array}{ll}\begin{array}{l}\text { Batik } \\
\text { Arum }\end{array} & \text { Sekar } \\
\end{array}$ & Bantul & SLTA & 1 & 30 & 2007 & 38 \\
\hline Batik Bantul & Bantul & SMA & 1 & 9 & 2005 & 50 \\
\hline Batik Farras & $\begin{array}{l}\text { Kulon } \\
\text { Progo }\end{array}$ & SMP & 1 & 30 & 2006 & 41 \\
\hline Sembung Batik & $\begin{array}{l}\text { Kulon } \\
\text { Progo }\end{array}$ & SMP & 1 & 40 & 2010 & 42 \\
\hline $\begin{array}{l}\text { Batik } \\
\text { Kalimosodo }\end{array}$ & $\begin{array}{l}\text { Gunung } \\
\text { Kidul }\end{array}$ & SMA & 1 & 13 & 2007 & 39 \\
\hline $\begin{array}{ll}\text { Daru } & \text { Batik } \\
\text { Tancep } & \end{array}$ & $\begin{array}{l}\text { Gunung } \\
\text { Kidul }\end{array}$ & STM & 1 & 30 & 2007 & 39 \\
\hline $\begin{array}{l}\text { Omah Batik } \\
\text { Sekar Turi }\end{array}$ & Sleman & SMK & 1 & 10 & 2010 & 36 \\
\hline Nakula Sadewa & Sleman & S1 & 3 & 38 & 1997 & 54 \\
\hline
\end{tabular}

\section{(Informan)Sumber: Data Diolah.}

Pakaian jadi yang merupakan salah satu komoditi unggulan DIY termasuk di dalamnya ialah batik, seperti yang diulas tempo (2015) bahwa pangsa pasar batik di Yogyakarta sedang menggeliat, terindikasi dengan sejumlah pengrajin telah memasarkannya hingga luar negeri dengan nilai omzet ekspor tekstil batik senilai US\$ 36,53 juta, sedangkan ekspor pakaian batik mencapai US\$ 11 juta. Hal sama diulas Harian jogja (2016) bahwa kondisi ekspor DIY 2015 skitar US\$ 11 juta dan januariagustus sbesar US\$ 8,3 juta sehingga ada peningkatan sebsar $7,17 \%$ dibanding priode yang sama.

\section{HASIL DAN DISKUSI PENELITIAN}

Penelitian ini dilakukan dari tanggal 20 Februari 2017 - 3 April 2017 melibatkan 10 pelaku usaha batik skala UKM yang berlokasi di Provinsi DIY dengan karakteristik Subyek penelitian berikut pada tabel 4.

Tabel 4. Karakteristik Subyek Penelitian

\begin{tabular}{|l|l|l|l|l|l|l|l|}
\hline \multicolumn{2}{|l|}{ Pendidikan } & \multicolumn{2}{l|}{ Usia (Tahun) } & \multicolumn{2}{l|}{ Tahun Berdiri } & \multicolumn{2}{l|}{ Alasan Pendirian } \\
\hline Tingkatan & Jumlah & Range & Jumlah & Range & Jumlah & Alasan & Jumlah \\
\hline SMP & 2 & $26-30$ & 5 & $1995-2000$ & 2 & Turunan & 3 \\
\hline SMA & 5 & $31-35$ & 4 & $2001-2005$ & 1 & $\begin{array}{l}\text { Lingkun } \\
\text { gan }\end{array}$ & 4 \\
\hline S1 & 3 & $36-40$ & 1 & $2006-2010$ & 7 & Peluang & 3 \\
\hline
\end{tabular}

Berdasarkan wawancara mendalam ditemukan beberapa permasalahan yang dihadapi pelaku perusahaan keluarga sekala UKM di DIY seabgai berikut:

\begin{tabular}{|l|l|}
\hline $\begin{array}{l}\text { Permaslaahan } \\
\text { internal }\end{array}$ & \multicolumn{2}{|l|}{ Permasalahan eksternal } \\
\hline \multicolumn{1}{|l|}{$\begin{array}{l}\text { Sense of Art } \\
\text { dan }\end{array}$} & - Jumlah pelaku \\
Pemaknaan & usaha semakin \\
/Filosofi & - - Masih \\
\hline
\end{tabular}




\begin{tabular}{|c|c|}
\hline $\begin{array}{l}\text { motif batik } \\
\text { yang bisa } \\
\text { menjadi } \\
\text { nilai seni } \\
\text { tinggi } \\
\text { kurang } \\
\text { dipahami. } \\
\text { - Manajemen } \\
\text { bisnis dan } \\
\text { SDM yang } \\
\text { minim. } \\
\text { Pemahama } \\
\mathrm{n} \text { dan } \\
\text { Kemampua } \\
\mathrm{n} \text { Inovasi } \\
\text { yang } \\
\text { minim. }\end{array}$ & $\begin{array}{l}\text { minimnya Etika } \\
\text { (fair trade) antar } \\
\text { pengrajin atau } \\
\text { pelaku usaha } \\
\text { batik. } \\
\text { Adanyapengaruh } \\
\text { kondisi ekonomi } \\
\text { Negara } \\
\text { langganan atau } \\
\text { tingkat daya beli } \\
\text { domestik } \\
\text { terhadap } \\
\text { penjualan } \\
\text { perusahaan. } \\
\text { Maraknya batik } \\
\text { printing, } \\
\text { didukung } \\
\text { dengan belum } \\
\text { meratanya } \\
\text { pengetahuan/pen } \\
\text { ghargaan } \\
\text { konsumen } \\
\text { terhadap batik. }\end{array}$ \\
\hline
\end{tabular}

Pelaku usaha menempatkan inovasi sebagai strategi yang sangat penting dalam menghadapi dan mengatasi permasalahan dan tantangan yang dihadapi, baik permasalahan internal maupun eksternalnya seperti yang diuraikan sebelumnya. Inovasi tersebut bisa melalui inovasi produk, proses, administrasi, dan inovasi distribusi. Keempat inovasi tersebut bisa dijelaskan sebagai berikut:

1. Inovasi produk, inovasi yang diwakili oleh adanya produk atau jasa baru yang diperkenalkan untuk memenuhi kebutuhan pasar.

2. Inovasi Proses/teknis, mengacu pada produk atau layanan dan teknologi dalam proses produksi.

3. Inovasi adminstrasi/organisasi, inovasi yang melibatkan struktur organisasi dan proses administrasi.

4. Inovasi distribusi/marketing chanel, bagian elemen baru yang diperkenalkan dalam rangka menjangkau konsumen.

Dari ke empat inovasi tersebut, tidak semua inovasi tersebut bisa atau mampu pelaku usaha lakukan, dan dari sepuluh pelaku usaha yang menjadi subyek penelitian ini, semuanya memberikan perhatian besar pada inovasi produk, setengahnya pada inovasi distribusi dan sedikit sekali yang memberi perhatian pada proses maupun administrasi/ organisasi. Temuan ini dibuat sederhana dalam figur 1 berikut;

Figur 1. Pattern inovasi pelaku usaha batik sekala UKM

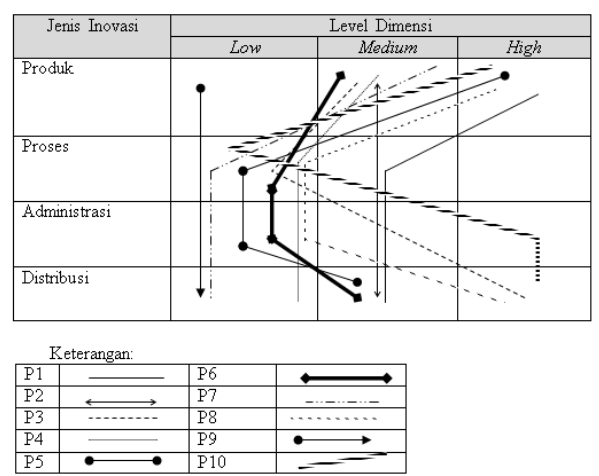

Tabel 6. Dimensi Inovasi \& Karakteristiknya

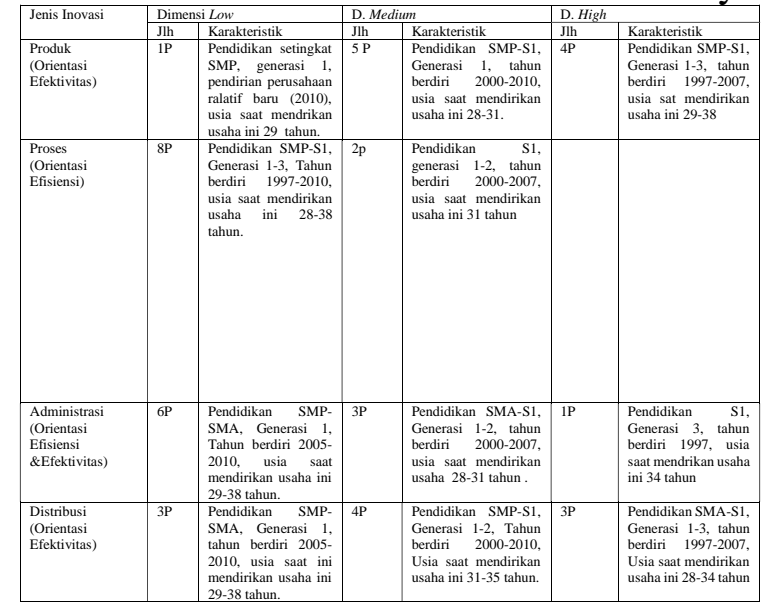

Berdasar temuan sebelumnya bahwa pola inovasi pelaku usaha cenderung melakukan inovasi produk dan distribusi yang berada pada level medium-high, dengan kata lain strategi inovasi pelaku usaha batik skala UKM adalah strategi yang berorientasi efektivitas melalui upaya eksplorasi pada inovasi produk dan inovasi distribusi. Namun bila temuan tersebut dikonsepsikan ke dalam strategi inovasi menggunakan tiga pendorong utama strategi inovasi kataria (2013) yaitu (1) Kepemimpinan kewirausahaan,

Diversfikasi Tim Manajemen Puncak, (3) Mekanisme belajar yang disengaja 
Figur 2. Permasalahan dan solusi UKM

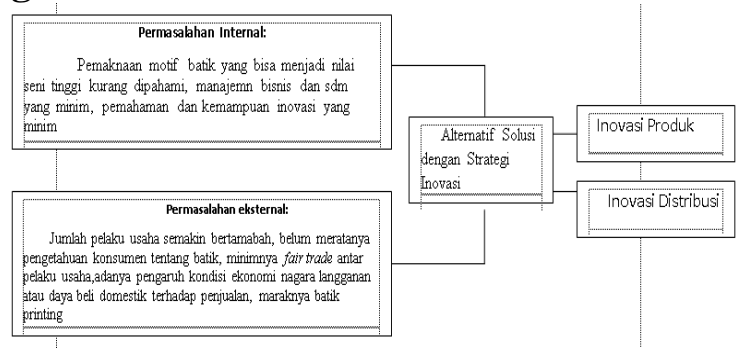

\section{Diskusi Penelitian}

Industri batik bisa dikatakan sebagai industri yang memiliki pasar stabil tidak seperti industri pada pasar teknologi dimana perubahan begitu cepat terjadi, namun demikian keberadaan strategi inovasi dalam industri batik ini dirasa sangat penting untuk menciptakan keunggulan guna keberlangsungan perusahaan. Hal ini terlihat dari hampir semua subyek dalam penelitian mengungkapkan bahwa inovasi sangat penting, hingga temuan melihatkan strategi inovasi dijadikan sebagai alternatif solusi mengatasi beberapa permasalahan yang dihadapi. Temuan dilapangan ini bisa menjadi kritisasi bagi penelitian kataria (2013) bahwa strategi inovasi tidak hanya untuk konsep dipasar tidak stabil namun juga untuk pasar stabil, selain itu bisa menjadi catatan bahwa tiga dari pendorong utama strategi inovasi yang ditemukan dalam perusahaan skala UKM hanya kepemimpinan kewirausahaan yang bisa dikatakan sebagai pendorong utama strategi inovasinya.

Bila temuan penelitian tersebut dikaitkan dengan tipologi strategi Miles \& Snow (1978) maka bisa dikatakan masuk tipe strategi prospector, yaitu tipe strategi yang memperlakukan lingkungan lebih dinamis dengan perhatian utamanya pada eksploitasi produk dan peluang pasar yang baru. Para pelaku usaha dalam industri batik skala UKM sangat mendambakan produk yang dihasilkan terimplikasi dengan tingkat perhatian inovasi produk yang tinggi dalam industri ini. Selain itu, para pelaku usaha juga memandangi lingkungan bisnis dalam industri ini sangat dinamis yang terimplikasi dengan perhatian pelaku usaha yang juga cukup besar pada inovasi distribusi. Dengan demikian, tipe strategi Prospectore dengan pola inovasi produk dan distribusi menjadi fokusnya merupakan strategi jangka panjangnya para pelaku usaha skala UKM pada industri batik.

\section{Kesimpulan Penelitian}

Beberapa hal yang dapat diambil kesimpulan dari penelitian ini yaitu:

1. Pola inovasi perusahaan keluarga skala UKM berorientasi pada efektivitas yang teridentifikasi dengan dimensi level medium-high pada inovasi produk dan inovasi distribusi, berkorelasi dengan tingkat kewirausahaan (entrepreneurship) pelaku usaha yang tercermin dari pengalaman atau lamanya berkecimpung dalam bisnis khususnya pada industri batik.

2. Strategi inovasi perusahaan keluarga skala UKM ialah berorientasi pada efektivitas melalui upaya berinovasi pada produk dan distribusi dengan kepemimpinan kewirausahaan (Leadership entrepreneurship) sebagai pendorong utamanya.

3. Pola inovasi yang dilakukan oleh perusahaan keluarga skala UKM pada industri batik tidak cukup atau tidak menjamin para pelaku usaha bisa bersaing dalam jangka panjang, sehingga perlu mempertimbangkan pola inovasi lainnya juga.

\section{DAFTAR PUSTAKA}

Afrizal. 2014. Metode Penelitian Kualitatif. Jakarta: PT Raja Grafindo Persada.

Andriani, Dwi. 2013. 40\% Pebisnis Pemula Gagal, Ini 3 Cara Supaya Bisnis Anda Bisa Bertahan Lama. Diaksesdarihttp:// entrepreneur.bisnis.com/.Oktober 2016.

Beyene, K.T, C.S. 2016. The Impact of Innovation Strategy on Organizational Learning and Innovation Performance: Do Firm Size and Ownership type Make A Diference.Journal of Industrial Engineering May 2016 Vol 27(1). South African: Ethiopian Institute of Technology. 
BPS. 2016. Provinsi DIY Dalam Angka. Yogyakarta: BPS DIY.

Chesbrough H. 2010. Business model innovation: opportunities and barriers. Long Range Plann 43(23):354-363.

Damanpour, F., (1991), Organizational Innovation: Ameta-analysis of effects of determinants and moderators, Academy of management journal, Vol.34/ No.3

Frenz, M, Lambert, R. 2012. Mixed Modes of Innovation: an Empiric Approach to CapturingFirms, Innovation Behaviour. OECD Science, Technology and Industry Working Papers, OECD Publishing.

Hakim , Luqman. 2016. DIY dorong perajin batik tingkatkan daya saing. Diakses dari .

http://jogja.antaranews.com oktober 2016.

Hartini, Sri. 2012. Peran Inovasi: Pengembangan KualitasProduk dan Kinerja Bisnis. Jurnal Manajemen dan kewirausahaan: FEB Air Langga.

Julianto, Pramdia Arhando. 2016. Industri Fashion, Kerajinan, dan Kuliner Tumbuh Pesat di Indonesia. Diakses dari http://bisniskeuangan.kompas.com/.

Kataria, S. 2013. Strategic Innovation: $A$ Review a Theory Framework. Thesis:

Lani, Pujiastuti. 2015. Diakui Dunia, Ekspor Batik RI Meningkat Setiap Tahun. http://finance.detik.com/. Akses oktober 2016.Hakim , Luqman. 2016. DIY dorong perajin batik tingkatkan daya saing. Diakses dari . http://jogja.antaranews.com oktober 2016.

Lo, Yitung. 2008. Comparing fashion innovators and non-innovators' characteristics and perceptions.Thesis. Lowa: Master of Science Lowa State University.

Miles, R.E \& Snow, C.C. 1978. Organizational strategy, Structure, and Process. Article in The Academy of Management Review .

Pachouru, Anshul \& SHarm, Sankaip. 2016. Barries to Innovation in Dinidan Small and Medium Size Enterprises. ADB Paper no 588.

Preda, Gheorghe. 2009. The Strategic Innovation: Conceptual Framework. International Conference "Marketing - from information to decision" 2nd Edition: The West University of Timişoara, Faculty of Economics and Business Administration.

Qomah, kusnul I. 2016. Pertumbuhan Ekonomi DIY. Harianjogja.com. Diakses juni 2017.

Rahadi, Raden Aswin. 2016. Opportunity and Challenges for Micro-Small and Medium Businees Indonesia Facing Asean economic Comunity. JMK, VOL. 18, NO. 1. Malysia: University Malaysia Terengganu.

Ramadani, Veland \& Gerguri, Shqipe. 2010. Innovation: Principles and Strategies. MPRA. Tetovo: SouthEast European University.

Rudiana, Pito A. 2015. Status Yogyakarta jadi Kota Batik Dunia Terancam Dicabut:

https://m.tempo.co/read/news.

Diakses Maret 2017.

Storey, D. 1994.Understanding the Small Business Sector. London: Routledge

Sudaryanto\& Wagimun \& Wijayanti, Rahma R. 2011. Strategi pemberdayaan UMKM Menghadapi Pasar Bebas Asean. Jurnal. Jember: FE UNJ.

Zou, Won-jiedkk.2014. Performace Appraisal between Family Busness and non Family Business.The International Journal of Organizational Innovation $\mathrm{Vol} 7$ Num 1. 